\title{
Molecular Interaction Studies of Benzyl Alcohols with Methacrylates in Carbon Tetrachloride using Frequency Domain Technique
}

\author{
S. RADHAKRISHNAN ${ }^{1,2}$, K. RAMACHANDRAN ${ }^{3}$ and K.SAMUVEL ${ }^{3}$ \\ ${ }^{1}$ Research and Development Centre, Bharathiar University, Coimbatore-641 046, Tamilnadu, India. \\ 2Department of Physics, Sriram Engineering College, Perumalpattu-602 024, Tamilnadu, India. \\ ${ }^{3}$ Department of Physics, Vadapalani Campus, SRM University, Chennai-600 026, Tamilnadu, India. \\ ${ }^{*}$ Corresponding author E-mail address: kaviramach76@gmail.com \\ http://dx.doi.org/10.13005/ojc/320440
}

(Received: June 27, 2016; Accepted: August 09, 2016)

\begin{abstract}
The dielectric relaxation of benzyl alcohol substitutents (benzyl alcohol, $m$-methylbenzyl alcohol and $m$-nitrobenzyl alcohol) with methyl methacrylate and butyl methacrylate in dilute solution of carbon tetrachloride is measured at $9.37 \mathrm{GHz}$ using Frequency domain (X-band) technique. Different dielectric parameters like dielectric constant $\left(\varepsilon^{\prime}\right)$, dielectric loss factor $\left(\varepsilon^{\prime \prime}\right)$ at Microwave frequency, static dielectric constant $\left(\varepsilon_{0}\right)$ and dielectric constant at infinite dilution $\left(\varepsilon_{\infty}\right)$ at optical frequency have been determined. From the measured dielectric data, the relaxation time $(\tau)$ calculated using Higasi method and activation energies $\left(\Delta \mathrm{F}_{\mathrm{t}}\right.$ and $\left.\Delta \mathrm{F}_{\eta}\right)$ have been determined. All the dielectric parameters that are vary with the substitutent change in benzyl alcohol and chain length of acrylic esters. Suggests that, the proton donating ability is varying with the substitution of benzyl alcohol and proton accepting ability is varying with the chain length of acrylic esters. The relaxation time and molar free energy activation of $1: 1$ molar ratio is greater than other higher molar ratios (i.e. 3:1, 2:1, 1:2, $1: 3)$ confirm that the existence of most likely $1: 1$ complex formation between the studied systems and also complex formation formed between free hydroxyl group of substituted benzyl alcohols and carbonyl group of acrylic esters (MMA and EMA).
\end{abstract}

Keywords: Relaxation time, Activation free energy, Benzyl alcohol, Methyl methacrylate, Butyl methacrylate.

\section{INTRODUCTION}

Benzyl alcohol and its substitutents are found in the natural products and used for mechanistic investigation ${ }^{3,10,14}$. Benzyl alcohol is used as a general solvent for inks, paints, lacquers, and epoxy resin coatings. It is also a precursor to a variety of esters, used in the soap, perfume, and flavor industries, as well as for pharmaceuticals ${ }^{7}$. It exhibits bacteriostatic and antipruritic properties. It is 
also used as a photographic developer. Acrylic esters are industrially important chemicals and precursors in the synthesis of polymers ${ }^{15}$. Methacrylates are an important monomer for a synthetic polymer poly, which is an excellent substitute for glass and has a wider area of use in dental and industrial applications ${ }^{15}$. Dielectric studies of liquid in pure state or in inert solvents have remained a subject of interest ${ }^{4}$ because they provide useful information about the complex formation in solution. The dielectric relaxation studies are useful to investigate intermolecular and intramolecular interactions ${ }^{6}$. Liakath Ali Khan et al., ${ }^{12}$ have investigated the complex formation of acrylic esters with phenol derivatives in non-polar solvents using frequency domain technique. Singh et al., ${ }^{16}$ have studied the relaxation mechanism of some substituted alcohols using NMR techniques. Singh and Sinha ${ }^{17}$ measured the dielectric constant for benzyl alcohol with 1-hexanol in non-polar solvents. Dharmalingam et al., ${ }^{1}$ have reported the hydrogen bonding between acrylic esters with aliphatic alcohols in non-polar solvents through dielectric studies. Keeping both the industrial and scientific interest in mind, an attempt has been made in this research paper to study the hydrogen bonding between aromatic alcohols and ester using dielectric method.

\section{Experimental Section and method}

\section{Materials}

Methyl methacrylate, Butyl methacrylate, benzyl alcohol, m-methylbenzyl alcohol, and $m$-nitrobenzyl alcohol with purity $>99 \%$ (spectroscopic grade) were purchased from Aldrich and used without any further purification. AR grade carbon tetrachloride was purified by standard method ${ }^{19}$ and redistilled before use. The physical parameters of all the chemicals used in this study were checked against their literature values.

\section{Dielectric Measurements}

The static dielectric constants were measured by heterodyne beat method at $308 \mathrm{~K}$ using a commercial instrument, Dipolemeter DM 01 supplied by Wissenschaijftlich Technische Werkstatter, Germany, operated at 220 V. The refractive indices were measured by Abbe's refractometer. The measurements of dielectric constant at an angular frequency $\left(\varepsilon^{\prime}\right)$ and dielectric loss $\left(\varepsilon^{\prime \prime}\right)$ were carried out in the X-band microwave frequency of $9.37 \mathrm{GHz}$. The viscosities were measured with the help of Oswald's viscometer. The temperature of all these measurements was maintained at $35 \pm 0.1^{\circ} \mathrm{C}$ using a water circulating thermostat.

\section{Theory}

According to the method of Higasi et al., ${ }^{5}$ the individual relaxation time $\tau_{(1)}$ is described by

$\tau_{(1)}=\frac{a^{\prime \prime}}{\omega\left(a^{\prime}-a_{\infty}\right)}$ given by,

While the overall dielectric relaxation $\tau_{(2)}$ is

$$
\tau_{(2)}=\frac{a_{0}-a^{\prime}}{\omega d^{\prime \prime}}
$$
is given by,

and the most probable relaxation time $\tau_{(0)}$ $\tau_{(0)}=\sqrt{\tau_{(1)} \tau_{(2)}}$

Where, $\omega$ is the angular frequency; $\alpha_{0}, \alpha^{\prime}$, $\alpha$ ", and $\alpha$ are defined by the following:

$\varepsilon_{0}=\varepsilon_{01}+a_{0} \mathrm{w}_{2}, \varepsilon^{\prime}=\varepsilon_{1}+a^{\prime} \mathrm{w}_{21} \varepsilon^{\prime \prime}=a^{\prime \prime} \mathrm{w}_{2}, \varepsilon_{\infty}=\varepsilon_{1 \infty}+a_{\infty} \mathrm{w}_{2}$

in which subscript 1 refers to the pure solvent, 2 refers to the solute, 0 refers to the static frequency, and $¥$ refers to the infinite or optical frequency measurements, and $w_{2}$ is the weight fraction of the solute.

The molar free energy of activation, for both dielectric relaxation $\Delta \mathrm{Ft}$ as well as the viscous flow processes $\Delta F \eta$ has been evaluated using the equations given by Eyring et al.,2

$$
\tau=\frac{\mathrm{h}}{\mathrm{kT}} \exp \left(\frac{\Delta \mathrm{F}_{\tau}}{\mathrm{RT}}\right) \quad, \quad \eta=\frac{\mathrm{Nh}}{\mathrm{V}} \exp \left(\frac{\Delta \mathrm{F}_{\eta}}{\mathrm{RT}}\right)
$$

Where $h$ is Plank's constant, $k$ is Boltzmann constant, $N$ is Avogadro's number, and $V$ is the molar volume 


\section{RESULTS AND DISCUSSION}

The value of dielectric constant $\left(\varepsilon^{\prime}\right)$, dielectric loss ( $\left.\varepsilon^{\prime \prime}\right)$, dielectric constant at static frequency $\left(\varepsilon_{0}\right)$, dielectric constant at angular frequency $\left(\varepsilon_{\ddagger}\right)$, the relaxation time due to the individual molecular rotations $\left(t_{(1)}\right)$, the relaxation time due to the whole or overall molecular rotations $\left(\tau_{(2)}\right)$, the most probable

Table 1: Static dielectric constant $\left(\varepsilon_{0}\right)$, dielectric constant at angular frequency $\left(\varepsilon_{0}\right)$, dielectric constant $\left(\varepsilon^{\prime}\right)$, dielectric loss $\left(\varepsilon^{\prime \prime}\right)$, dielectric relaxation time and activation energies $(\Delta \mathbf{F} \tau, \Delta \mathbf{F} \eta)$ for m-methylbenzyl alcohol with acrylic esters in carbon tetrachloride

\begin{tabular}{|c|c|c|c|c|c|c|c|c|c|c|}
\hline \multirow[t]{2}{*}{ Esters } & \multirow{2}{*}{$\begin{array}{l}\text { Ratio } \\
\text { Ester: } \\
\text { Alcohol }\end{array}$} & \multirow[b]{2}{*}{$\varepsilon^{\prime}$} & \multirow[b]{2}{*}{$\varepsilon^{\prime \prime}$} & \multicolumn{7}{|c|}{ Relaxation time (ps) } \\
\hline & & & & $\varepsilon_{\mathrm{o}}$ & $\varepsilon_{*}$ & $\tau_{(1)}$ & $\tau_{(2)}$ & $\tau_{(0)}$ & $\begin{array}{c}\Delta \mathbf{F}_{\tau} \\
\mathbf{k J} / \mathbf{m o l e}\end{array}$ & $\begin{array}{c}\Delta \mathbf{F}_{\eta} \\
\mathbf{k J} / \mathrm{mole}\end{array}$ \\
\hline \multirow[t]{7}{*}{ MMA } & $0: 1$ & 2.5116 & 0.2296 & 2.7652 & 2.1298 & 13.19 & 18.65 & 15.69 & & \\
\hline & $1: 3$ & 2.5536 & 0.2402 & 2.8526 & 2.2318 & 17.34 & 21.02 & 19.09 & & \\
\hline & $1: 2$ & 2.5702 & 0.2745 & 2.9874 & 2.2326 & 18.56 & 25.66 & 21.83 & & \\
\hline & $1: 1$ & 2.5889 & 0.2887 & 3.1178 & 2.2461 & 19.13 & 30.94 & 24.32 & 12.02 & 13.19 \\
\hline & $2: 1$ & 2.5713 & 0.2779 & 2.9865 & 2.2319 & 18.66 & 25.23 & 21.70 & & \\
\hline & $3: 1$ & 2.5574 & 0.2397 & 2.8528 & 2.2326 & 17.09 & 20.81 & 18.86 & & \\
\hline & $1: 0$ & 2.2845 & 0.0306 & 2.3046 & 2.1317 & 7.96 & 11.09 & 9.40 & & \\
\hline \multirow[t]{7}{*}{ BMA } & $0: 1$ & 2.5116 & 0.2296 & 2.7652 & 2.1298 & 13.19 & 18.65 & 15.69 & & \\
\hline & $1: 3$ & 2.5381 & 0.2305 & 2.8392 & 2.2418 & 18.68 & 22.06 & 20.30 & & \\
\hline & $1: 2$ & 2.5653 & 0.2608 & 2.9704 & 2.2483 & 19.22 & 26.23 & 22.45 & & \\
\hline & $1: 1$ & 2.5692 & 0.2793 & 3.0998 & 2.2507 & 20.45 & 32.08 & 25.61 & 12.52 & 14.18 \\
\hline & $2: 1$ & 2.5642 & 0.2619 & 2.9726 & 2.2454 & 19.15 & 26.33 & 22.46 & & \\
\hline & $3: 1$ & 2.5408 & 0.2321 & 2.8372 & 2.2403 & 18.44 & 21.56 & 19.94 & & \\
\hline & $1: 0$ & 2.2718 & 0.0204 & 2.2876 & 2.1516 & 10.66 & 13.08 & 11.81 & & \\
\hline
\end{tabular}

Table 2: Static dielectric constant $\left(\varepsilon_{0}\right)$, dielectric constant at angular frequency $\left(\varepsilon_{0}\right)$, dielectric constant $\left(\varepsilon^{\prime}\right)$, dielectric loss $\left(\varepsilon^{\prime \prime}\right)$, dielectric relaxation time and activation energies $(\Delta \mathbf{F} \tau, \Delta \mathbf{F} \eta)$ for benzyl alcohol with acrylic esters in carbon tetrachloride

\begin{tabular}{|c|c|c|c|c|c|c|c|c|c|c|}
\hline \multirow[t]{2}{*}{ Esters } & \multirow{2}{*}{$\begin{array}{l}\text { Ratio } \\
\text { Ester: } \\
\text { Alcohol }\end{array}$} & \multirow[b]{2}{*}{$\varepsilon^{\prime}$} & \multirow[b]{2}{*}{$\varepsilon^{\prime \prime}$} & \multirow[b]{2}{*}{$\varepsilon_{0}$} & \multirow[b]{2}{*}{$\varepsilon_{*}$} & \multicolumn{3}{|c|}{ Relaxation time (ps) } & \multirow[b]{2}{*}{$\begin{array}{c}\Delta \mathbf{F}_{\tau} \\
k J / m o l e\end{array}$} & \multirow[b]{2}{*}{$\begin{array}{c}\Delta \mathbf{F}_{\eta} \\
\mathrm{kJ} / \mathrm{mole}\end{array}$} \\
\hline & & & & & & $\tau_{(1)}$ & $\tau_{(2)}$ & $\tau_{(0)}$ & & \\
\hline \multirow[t]{7}{*}{ MMA } & $0: 1$ & 2.4537 & 0.1689 & 2.6834 & 2.1891 & 16.14 & 22.96 & 19.25 & & \\
\hline & $1: 3$ & 2.5012 & 0.2023 & 2.7917 & 2.2484 & 20.72 & 24.25 & 22.41 & & \\
\hline & $1: 2$ & 2.5216 & 0.2422 & 2.9302 & 2.2528 & 22.61 & 28.49 & 25.38 & & \\
\hline & $1: 1$ & 2.5398 & 0.2617 & 3.0686 & 2.2679 & 24.02 & 34.12 & 28.63 & 13.21 & 14.81 \\
\hline & $2: 1$ & 2.5221 & 0.2435 & 2.9324 & 2.2557 & 23.04 & 28.45 & 25.60 & & \\
\hline & $3: 1$ & 2.5034 & 0.2041 & 2.7947 & 2.2495 & 20.76 & 24.10 & 22.37 & & \\
\hline & $1: 0$ & 2.2845 & 0.0306 & 2.3046 & 2.1317 & 7.96 & 11.09 & 9.40 & & \\
\hline \multirow[t]{7}{*}{ BMA } & $0: 1$ & 2.4537 & 0.1689 & 2.6834 & 2.1891 & 16.14 & 22.96 & 19.25 & & \\
\hline & $1: 3$ & 2.4632 & 0.1723 & 2.7632 & 2.2593 & 25.08 & 29.40 & 27.16 & & \\
\hline & $1: 2$ & 2.4861 & 0.2084 & 2.8795 & 2.2634 & 26.11 & 31.88 & 28.85 & & \\
\hline & $1: 1$ & 2.5009 & 0.2273 & 3.0207 & 2.2709 & 27.01 & 38.62 & 32.30 & 13.59 & 14.54 \\
\hline & $2: 1$ & 2.4831 & 0.2075 & 2.8766 & 2.2618 & 26.27 & 32.02 & 29.00 & & \\
\hline & $3: 1$ & 2.4657 & 0.1764 & 2.7628 & 2.2584 & 24.95 & 28.44 & 26.64 & & \\
\hline & $1: 0$ & 2.2718 & 0.0204 & 2.2876 & 2.1516 & 10.66 & 13.08 & 11.81 & & \\
\hline
\end{tabular}


Table 3: Static dielectric constant ( $\left.\varepsilon_{\mathrm{o}}\right)$, dielectric constant at angular frequency $\left(\varepsilon_{\mathrm{o}}\right)$, dielectric constant $\left(\varepsilon^{\prime}\right)$, dielectric loss $\left(\varepsilon^{\prime \prime}\right)$, dielectric relaxation time and activation energies $(\Delta \mathbf{F} \tau, \Delta \mathbf{F} \eta)$ for m-nitrobenzyl alcohol with acrylic esters in carbon tetrachloride

\begin{tabular}{lcccccccccc}
\hline Esters & $\begin{array}{c}\text { Ratio } \\
\text { Ester: }\end{array}$ & $\varepsilon^{\prime}$ & $\varepsilon^{\prime \prime}$ & $\varepsilon_{\mathbf{o}}$ & $\varepsilon_{¥}$ & $\tau_{(1)}$ & $\tau_{(2)}$ & $\tau_{(0)}$ & $\Delta \mathbf{F} \tau$ & $\Delta \mathbf{F} \eta$ \\
& Alcohol & & & & & & & & & \\
kJ/mole kJ/mole & \\
\hline MMA & $0: 1$ & 2.3548 & 0.0217 & 2.4132 & 2.2576 & 39.40 & 45.44 & 42.32 & & \\
& $1: 3$ & 2.3741 & 0.0603 & 2.5542 & 2.2627 & 43.33 & 50.43 & 46.75 & & \\
& $1: 2$ & 2.3846 & 0.0901 & 2.6641 & 2.2638 & 46.24 & 52.38 & 49.22 & & 16.64 \\
& $1: 1$ & 2.4047 & 0.1176 & 2.8108 & 2.2778 & 50.92 & 58.31 & 54.49 & 15.75 & \\
& $2: 1$ & 2.3851 & 0.0937 & 2.6786 & 2.2632 & 46.54 & 52.89 & 49.61 & & \\
& $3: 1$ & 2.3742 & 0.0622 & 2.5551 & 2.2628 & 44.69 & 49.11 & 46.85 & & \\
& $1: 0$ & 2.2845 & 0.0306 & 2.3046 & 2.1317 & 7.96 & 11.09 & 9.40 & & \\
& $0: 1$ & 2.3548 & 0.0217 & 2.4132 & 2.2576 & 39.40 & 45.44 & 42.32 & & \\
& $1: 3$ & 2.3689 & 0.0411 & 2.4984 & 2.2671 & 49.93 & 53.21 & 51.54 & & \\
& $1: 2$ & 2.3797 & 0.0532 & 2.5708 & 2.2754 & 54.78 & 60.66 & 57.64 & & \\
& $1: 1$ & 2.3979 & 0.0737 & 2.6745 & 2.2888 & 58.70 & 63.37 & 60.99 & 16.68 & 17.51 \\
& $2: 1$ & 2.3793 & 0.0502 & 2.5603 & 2.2761 & 55.40 & 60.88 & 58.08 & & \\
& $3: 1$ & 2.3696 & 0.0405 & 2.5002 & 2.2682 & 50.66 & 54.45 & 52.52 & & \\
& $1: 0$ & 2.2718 & 0.0204 & 2.2876 & 2.1516 & 10.66 & 13.08 & 11.81 & & \\
\hline
\end{tabular}

relaxation time $\left(\tau_{(0)}\right)$ and the free energy of activation for dielectric relaxation process $(\Delta \mathbf{F} \tau)$ and viscous flow $(\Delta \mathbf{F} \eta)$ of proton donors ( $m$-methylbenzyl alcohol, benzyl alcohol and $m$-nitrobenzyl alcohol) with proton acceptor (methyl methacrylate and butyl methacrylate) in carbon tetrachloride at $308 \mathrm{~K}$ are shown in Tables 1, 2 and 3. A perusal of Tables 1,2 and 3 show that the values of e', e" and $e_{o}$ for substituted benzyl alcohols with carbon tetrachloride systems decrease in the order: $m$-methylbenzyl alcohol > benzyl alcohol > m-nitrobenzyl alcohol. This may be due to induced dipole moment of substituted benzyl alcohols increasing in the same sequence. In Table 1 to 3 , it is observed that the values of $\tau_{(2)}$ are significantly higher than $\tau_{(1)}$ and $\tau_{(0)}$ for all the systems. Higher values of $\tau_{(2)}$ indicate that the contribution of intermolecular or overall molecular relaxation is larger in comparison to intramolecular or individual molecular relaxation in the systems ${ }^{9}$. In the present study, it has been observed that the relaxation time of ternary mixtures (benzyl alcohol derivatives with MMA or BMA in $\mathrm{CCl}_{4}$ ) is much greater than the binary mixture (benzyl alcohol derivatives with $\mathrm{ccl}_{4}$ or MMA with $\mathrm{CCl}_{4}$ or BMA with $\mathrm{CCl}_{4}$ ). This result indicates that there is a hydrogen bond formation between the hydrogen atom in $\mathrm{O}-\mathrm{H}$ group of substituted benzyl alcohols and the oxygen atom in $\mathrm{C}=\mathrm{O}$ group of methacrylates, and is shown in Fig 1.

For a given methyl methacrylate, the relaxation times and activation energies values are increasing in the order: $m$-methylbenzyl alcohol $<$ benzyl alcohol < m-nitrobenzyl alcohol. This change in relaxation times and activation energies values indicates that the proton donating ability of proton donor varies with the substitution in benzyl alcohol. This may be due to acidity of benzyl alcohol increasing in the same sequence. By changing the type and number of substitutents in benzyl ring, the acidity can be regulated almost continuously. Further, the relaxation time and activation energies value decreases for electron donating groups (i.e., methyl) and increases for electron withdrawing groups (i.e., nitro) when compared with benzyl alcohol. This is because, the electron donating substitutents make the bond breaking process easier, whereas the electron withdrawing groups make the bond making process easier. This is well reflected with a lower relaxation times and activation energies values for electron donating groups and higher relaxation times and activation energies values for electron withdrawing groups with methacrylates. Therefore, 


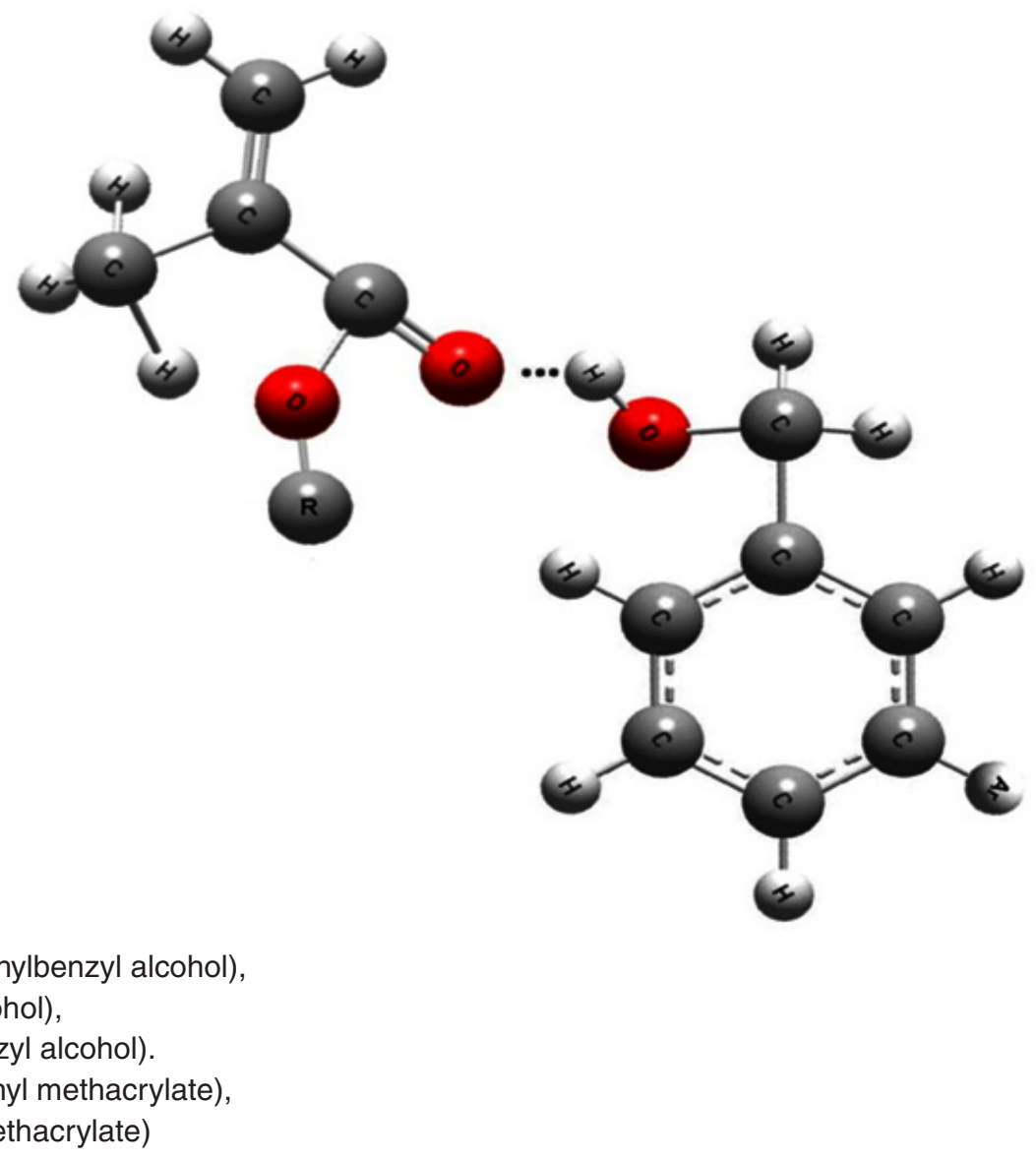

Fig. 1: Hydrogen bonding between meta substituted benzyl alcohols and acrylic esters

the strong hydrogen bond would be expected to form between $m$-nitrobenzyl alcohol with methacrylates in carbon tetrachloride and weakest hydrogen bond between $m$-methylbenzyl alcohol with methacrylates in carbon tetrachloride as reflected by the higher relaxation time for former systems and lower relaxation time for lesser systems. Similar results of methacrylates with phenol derivatives were carried out by Liakath Ali Khan et al., ${ }^{11}$.

Table1 shows that, the relaxation times of all studied systems are larger at 1:1 molar ratio than other higher molar ratios $(3: 1,2: 1,1: 2,1: 3)$. This indicates that the $1: 1$ complex formation is the predominant value in substituted benzyl alcohol methacrylates systems. Similar results were reported by Malathi et al., ${ }^{13}$ in some carbonyl + phenol derivative systems.

The molar free energy of activation for viscous flow $(\Delta \mathbf{F} \tau)$ and the free energy $(\Delta \mathbf{F} \eta)$ calculated for proton donors ( $m$-methylbenzyl alcohol, benzyl alcohol and $m$-nitrobenzyl alcohol) with proton acceptor (methyl methacrylate and butyl methacrylate) in carbon tetrachloride are presented in Table 2. It is evident from the data that the $\Delta \mathbf{F} \eta$ is $>\Delta \mathbf{F} \tau$. This is in agreement with the fact that the process of viscous flow, which involves both the rotational and translational forms of motion faces greater interference from neighbours than dielectric relaxation, which takes place by rotation only ${ }^{8}$. Smyth et al., ${ }^{18}$ pointed out that the relaxation time 
of a proton donor increases as the acceptor ability of the solvent environment increases. All the results are in complete accordance with this conclusion.

The values of $\tau_{(1)}, \tau_{(2)}, \tau_{(0)}, \Delta \mathrm{F} \tau$ and $\Delta \mathrm{F} \eta$ for acrylic esters with carbon tetrachloride are shown in Tables 1-3. They follow in the order: methyl methacrylate < butyl methacrylate. This indicates that the relaxation time varies in accordance with the size, shape and viscosity of the molecules. Further, the values of $\tau_{(1)}, \tau_{(2)}, \tau_{(0)}, \Delta F \tau$ and $\Delta F \eta$ for proton donors (substituted benzyl alcohols) with acrylic esters in carbon tetrachloride increase in the order: methyl methacrylate < butyl methacrylate for alkyl methacrylates. This trend suggests that the proton accepting ability of acrylic esters increases with increasing chain length i.e. butyl group of alkyl methacrylate has higher proton accepting ability than that of methyl groups of alkyl methacrylate. This is probably due to electron contribution of the butyl group to $\mathrm{C}=\mathrm{O}$ group which is significantly greater than that from methyl group.

\section{CONCLUSION}

The complex formation between substituted benzyl alcohols with methyl methacrylate and butyl methacrylate in carbon tetrachloride has been carried out using dielectric method. From this study, it may be concluded that the proton donating ability of substituted benzyl alcohols and the proton accepting ability of acrylic esters vary linearly with the substitution in benzyl alcohols and carbon chain length of acrylic esters and 1:1 complex formation is more predominant than other higher order complexes.

\section{REFERENCES}

1. Dharmalingam $K$, Sivagurunathan $P$, Ramachandran $\mathrm{K}$ and Kalamse $\mathrm{G} \mathrm{M}$, Molecular association of alkyl methacrylates and alcohols in non-polar solvents: Dielectric study, 2005.. 4(3) , 227-234

2. Eyring $\mathrm{H}$, Glasstone $\mathrm{S}$ and Laidler $\mathrm{K} \mathrm{J}$, The Theory of rate process, (Mc Graw Hill: New York). 1941.

3. Faubel M, Steiner B and Toennies P, Photoelectron spectroscopy of liquid water, some alcohols, and pure nonane in free micro jets. J. Chem. Phys, 1997. 106, 9013 -9031.

4. Gupta K K, Banshal A K, Singh P J and Sharma K S, Temperature dependence of dielectric relaxation of rigid polar molecules acetophenone, pyridine and their mixtures in dilute solutions of benzene. Indian J Pure \& Appl. Phys 2003. 41, 57-63.

5. Higasi K, Koga Y and Nakamura M, Dielectric Relaxation and Molecular Structure. V. Application of the Single Frequency Method to Systems with two Debye Dispersions. Bull Chem. Soc. Japan, 1971,.44, 988.-992.

6. Hill N E, Vaughan W E, Price A H and Davies $M$, Dielectric properties and molecular behaviour Reinhold, London 1969.

7. Huang T T, Ching-Ta Yeh and Chein-
Hsiun Tu,. Densities, Viscosities, Refractive Indices, and Surface Tensions for the Ternary Mixtures of 2-Propanol + Benzyl Alcohol + 2-Phenylethanol at $T=308.15 \mathrm{~K}$. J. Chem. Eng. Data, 2008 53, 1203-1207

8. Kalaivani T, Kumar S and Krishnan S, Dielectric relaxation studies of ternary liquid mixtures of alcohols with triethylamine in the microwave region. Ind. J. Chem. 2004. 43A, 291-294.

9. Khameshara S M, Kavadia M S, Lodha M S,Mathur D C and Vaidya V K, J Dielectric relaxation time and dipole moment of isometric butanols in benzene solutions $\mathrm{J}$. Mol. Liq., 1983. 26, 77-84.

10. Knop.S, Strassmair H, Engel J, Rothe $M$ and Steffen K D, Binding of benzyl alcohol to the peptide CO group of cyclotri-L-prolyl studied by infrared spectroscopy. Biopoly. 1972. 11,731-733.

11. Liakath Ali Khan F, Asghar J and Aravinthraj M, Dielectric Relaxation studies of $1: 1$ complexes of alkyl methacrylate with phenols derivatives. Rasayan J. of Chem. 2010. 3(4) 766-771.

12. Liakath ali khan $F$, Sivagurunathan $P$, and Asghar J,. Dielectric relaxation studies of alkyl acrylates with phenol derivatives in carbon 
tetrachloride using microwave absorption techniques. Indian J Pure \& Appl. Phys. 2008., 46, 54-59.

13. Malathi M, Sabesan R, Krishnan S, Dielectric relaxation of $\mathrm{N}, \mathrm{N}$-dimethyl formamide and $\mathrm{N}, \mathrm{N}$-dimethyl acetamide on complexation with phenols. Mat.Sci. and Engg. B. 2003. 100,318-322.

14. Matheu M.I, Echarri R and Castillón S, Synthesis of isochromane derivatives by metallocene-promoted reaction of 2-alkoxy2-fluoro-glycosyl fluorides with benzyl alcohol. Tetra. lett, 1993. 34, 2361-2365.

15. Schildknecht. C.E., "Vinyl and Related
Polymers" (Wiley: New York). (1977).

16. Singh A, Singh A K and Mehrotra N K, Study of NMR spin -lattice relaxation mechanism and mutual viscosity in some substituted alcohols. J. Mol. Liq. 2005. 121, 110-114.

17. Singh RP and Sinha $C P$, Dielectric behaviour of the ternary mixtures of toluene, chlorobenzene, 1-hexanol, and benzyl alcohol. J. Chem. Engg. Data 1985. 30(4), 474-476.

18. Smyth $\mathrm{C} P$, Ratajczak $\mathrm{H}$ and Orvile-thomas WJ (Eds), (1981). Molecular Interactions, Vol II, (Wiley: New York).

19. Weissberger A, Technique of Organic Chemistry, Wiley Interscience, New York (1970).. 